\title{
Indonesia and the United States Team up to Reduce Impacts from Dangerous Volcanoes
}

$\mathrm{Q}$ uiet since its 1963 eruptions killed more than 1,000 people, Mount Agung in Indonesia suddenly awoke in September 2017 from its long slumber with hundreds of felt earthquakes that caused great concern for the tens of thousands of people living nearby in eastern Bali. Steam emissions from the volcano were increasingly visible, and one question rose to the forefront of everyone's mind: was Mount Agung about to erupt again? Indonesia's Center for Volcanology and Geologic Hazards Mitigation (CVGHM) quickly mobilized, improving monitoring at local observatories near Agung and dispatching a rapidresponse team to Bali from their headquarters in Bandung, on the neighboring island of Java. Soon thereafter, members of the U.S. Geological Survey's (USGS) Volcano Disaster Assistance Program (VDAP) traveled from the United States to assist CVGHM with the rapidly escalating volcanic crisis.
With 75 historically active volcanoes, Indonesia is the world's most volcanically active nation. Its volcanoes are legendary throughout the world, with the notorious 19th-century eruptions at Mount Tambora (1815) and Krakatau (1883), and the eruption that created the giant Toba Caldera in Sumatra $(75,000$ years ago) - the Earth's largest volcanic eruption in the past 100,000 years. Just in the past 20 years, more than 36 volcanoes have erupted, some multiple times, threatening millions of people. The Government of Indonesia responds to this daunting volcanic threat from CVGHM's offices in Bandung. From there, dozens of staff members coordinate operations at 77 small observatories spread out across the 5,000-kilometer-long (3,100-mile-long) archipelago that is Indonesia.

For more than 50 years, the United States has worked in partnership with the Government of Indonesia to reduce the risk of volcanic eruptions and to save lives. Today, the two governments cooperate through an agreement between CVGHM and VDAP. The work is funded by the U.S. Agency for International Development (USAID) together with the USGS Volcano Hazards Program. Each year CVGHM and VDAP representatives convene to discuss priorities for the upcoming 12 months. They outline a series of training efforts, field campaigns, equipment deployments, and timely topics that require further exploration and development.

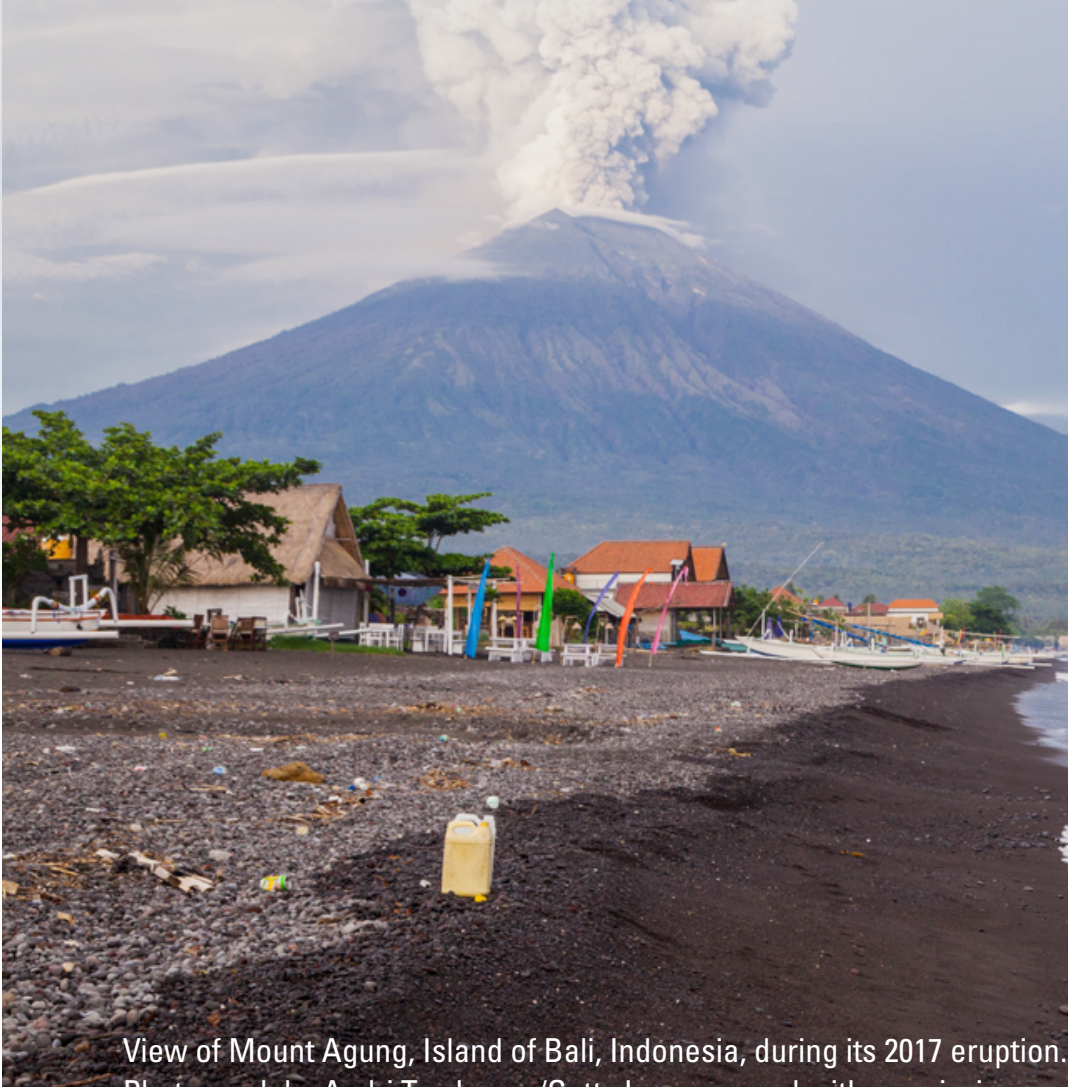

Photograph by Andri Tambunan/Getty Images, used with permission. 

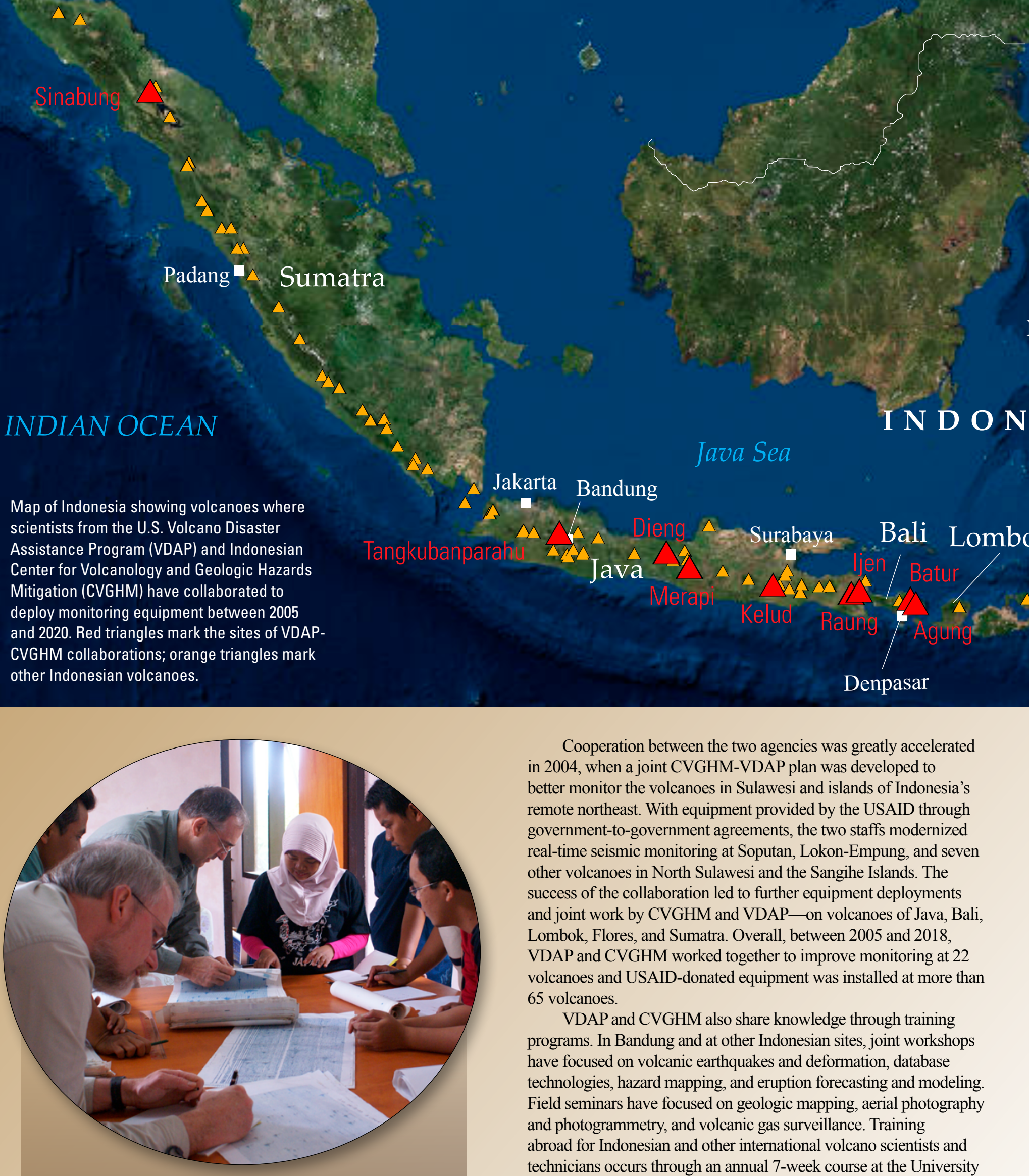

Cooperation between the two agencies was greatly accelerated in 2004, when a joint CVGHM-VDAP plan was developed to better monitor the volcanoes in Sulawesi and islands of Indonesia's remote northeast. With equipment provided by the USAID through government-to-government agreements, the two staffs modernized real-time seismic monitoring at Soputan, Lokon-Empung, and seven other volcanoes in North Sulawesi and the Sangihe Islands. The success of the collaboration led to further equipment deployments and joint work by CVGHM and VDAP — on volcanoes of Java, Bali, Lombok, Flores, and Sumatra. Overall, between 2005 and 2018, VDAP and CVGHM worked together to improve monitoring at 22 volcanoes and USAID-donated equipment was installed at more than 65 volcanoes.

VDAP and CVGHM also share knowledge through training programs. In Bandung and at other Indonesian sites, joint workshops have focused on volcanic earthquakes and deformation, database technologies, hazard mapping, and eruption forecasting and modeling. Field seminars have focused on geologic mapping, aerial photography and photogrammetry, and volcanic gas surveillance. Training abroad for Indonesian and other international volcano scientists and technicians occurs through an annual 7-week course at the University of Hawaii's Center for the Study of Active Volcanism in Hilo, Hawaii, and USGS Cascades Volcano Observatory in Vancouver, Washington, both in the United States. This VDAP-sponsored course is taught partly by VDAP staff and each year introduces one or more CVGHM staff to other volcano observatory staff and students from all over the world. Finally, VDAP supports travel for CVGHM staff to select international meetings to share their knowledge and research results with the global volcanology community.

Workshops between collaborators from the U.S. Geological Survey (USGS) and Indonesia's Center for Volcanology and Geologic Hazards Mitigation focus on best practices for a wide variety of situations. Here, USGS Volcano Disaster Assistance Program staff and their Indonesian colleagues review seismic data to identify earthquake characteristics that may be useful as eruption precursors. Photograph by Jeffrey Marso, USGS. 



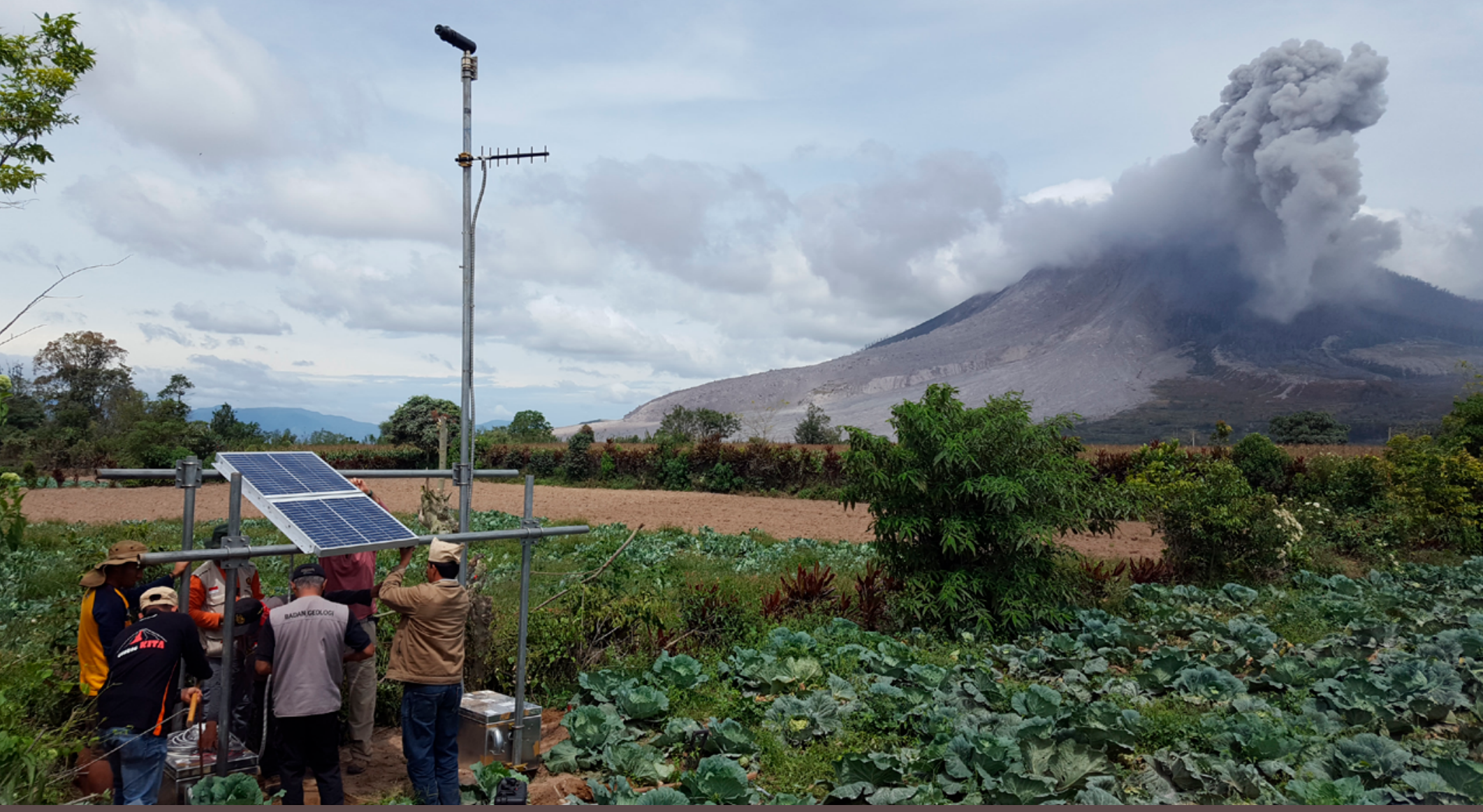

Installation of a telemetered, solar-powered scanning spectrometer in 2016 at Sinabung volcano-which has been continuously erupting since 2013 - in Sumatra, Indonesia. The instrument is used to measure the amount of sulfur dioxide gas emitted from the volcano, which helps scientists understand and forecast volcanic eruptions. Photograph by Christoph Kern, USGS

in statistical models to help make reliable forecasts. Such tools proved helpful in 2015, when VDAP worked with CVGHM to estimate that lava emissions at Sinabung volcano in northern Sumatra were likely to extend for a number of years, and that long-term evacuations and community planning might be necessary.

One recent focus for VDAP and CVGHM has been at Kawah Ijen, a dangerous acid lake in eastern Java. "Wet" volcanoes such as Ijen pose different challenges for monitoring because changes in temperature and gas discharge are masked by the presence of large water bodies. The Kawah Ijen lake itself poses a hazard, as slugs of toxic gas periodically burst through and pose risks to miners, tourists, and local communities. Recently, gas monitoring stations and a multinational workshop organized by CVGHM at Kawah Ijen afforded new insights into the dynamics of gas output from the volcano and the seasonal buildup of toxic gas. Through training and mentorship, CVGHM staff have become experts at deploying and maintaining USGS-designed and VDAP-donated gas monitoring equipment.

No country faces more volcanic risk and experiences more erupting volcanoes than Indonesia. By accepting assistance from foreign countries, CVGHM has been able to make giant strides in growing their monitoring networks and training their staff. International partnerships serve both CVGHM, but also the foreign collaborators that provide the support. In addition to the United States (through VDAP), Japan, Belgium, Australia, France, Singapore, and others assist CVGHM and its efforts to mitigate the effects of volcanic eruptions. Together, they gain invaluable experience testing new instruments, refining software tools, evaluating protocols to enhance community preparedness, and understanding volcanism at some of the world's most active volcanoes.
During increasing volcanic unrest in September and October 2017, more than 130,000 people were evacuated from their homes near Mount Agung. CVGHM and VDAP staff collaborated to install and repair monitoring equipment, improve computer systems, model potential eruption scenarios, analyze seismic and ground deformation data, and develop new strategies for sampling gases in volcanic clouds. After a month of intense earthquake activity, the volcano temporarily quieted in mid-October, but then finally erupted in late November 2017 and into the following year. The eruption was relatively small and no one was injured, but the volcanic episode at Mount Agung taught valuable lessons to CVGHM and their VDAP collaborators, and further strengthened a notable decades-old partnership.

Jacob B. Lowenstern, Kasbani, John S. Pallister, and David W. Ramsey

Edited by Monica Erdman

Layout and design by Cory Hurd

For more information, contact:

Volcano Disaster Assistance Program

Jacob B. Lowenstern, Chief

jlwnstrn@usgs.gov

vdap@usgs.gov

Center for Volcanology and Geological Hazard Mitigation

Kasbani, Chief

pvmbg@esdm.go.id 